\title{
Wide Excision with Immediate Reconstruction of the Mandible Using Free Fibular Flap in Ameloblastoma of the Mandible-A Need of Time: Our Experience of 37 Cases
}

\author{
Hemant A. Saraiya ${ }^{1}$ \\ ${ }^{1}$ Saraiya Plastic Surgery and Burns Hospital, Gujarat Cancer and \\ Research Institute, Ahmedabad, Gujarat, India
}

\begin{abstract}
Address for correspondence Hemant A. Saraiya, MS, MCh, 14, Vijaypark Society, Nr. Rabari Vasahat, Navrangpura, Ahmedabad 380 009, Gujarat, India (e-mail: drhemantsaraiya@yahoo.com).
\end{abstract}

\author{
Abstract \\ Keywords \\ - ameloblastoma \\ - free fibular flap \\ - microvascular surgery \\ - radical excision \\ - mandible \\ - free flap \\ - microvascular \\ anastomosis
}

Background Ameloblastoma is a benign yet locally aggressive odontogenic tumor of the jaw with high recurrence rates. Despite many studies, the search is still on for the treatment approach which can render the acceptable recurrence rates with good functional and esthetic results.

Methods In this prospective study, we operated on 37 patients of mandibular ameloblastoma between 2009 and 2018. Two patients were treated with curettage and chemical sterilization of the cavity. Resection of a tumor with a 2-cm margin was performed in the rest of 35 patients. The mandibular defect was primarily reconstructed with the microvascular free fibular flap in 29 patients.

Results The follow-up ranged from 6 months to 7.7 years with a mean of 5.1 years. A tumor recurred within a year in all two patients (100\%) treated with curettage. Out of 35 radical excisions, only one patient (2.85\%) developed recurrence 3 years after the disease-free interval. Good mouth opening, intelligible speech, satisfactory lower jaw shape, and facial profiles were achieved in all 29 patients who were treated with primary free fibular flap.

Conclusion We prefer wide excision with 2-cm margins on each side of a tumor with the primary reconstruction of the mandible in all cases of mandibular ameloblastoma. The free fibular microvascular flap is our treatment of choice as all defects of the mandible can be reconstructed with the free fibular flap. Wide excision is the key to prevent a recurrence.

\section{Introduction}

The estimated incidence of ameloblastoma is approximately 0.5 per million population per year. ${ }^{1}$ Of all swellings of the oral cavity, $10 \%$ are odontogenic tumors, and within this group, ameloblastoma accounts for $1 \%$ of the lesions. ${ }^{2}$ According to the World Health Organization (WHO) classification ${ }^{3}$ benign ameloblastoma consists of four subtypes being the solid/multicystic, the desmoplastic, the unicystic, and the extraosseous/ peripheral type, while malignant ameloblastoma includes metastasizing ameloblastoma and ameloblastic carcinoma.
Ameloblastoma ${ }^{4}$ commonly presents as a slow growing, painless swelling, with the expansion of the cortical bone, perforation of the lingual, and/or buccal plates and infiltration of soft tissue. There is often a delay in the diagnosis because of its slow-growing nature. On radiological examination, most cases have a characteristic unilocular radiolucent area or a multilocular radiolucent area with a honeycomb appearance. There may be resorption of adjacent teeth. Computed tomography and magnetic resonance imaging (MRI) help to establish the extent of the lesion. Biopsy, published online

November 24, 2020
Dol https://doi.org/

10.1055/s-0040-1719198 ISSN 0970-0358.

\section{(c) 2020. Association of Plastic Surgeons of India.}

This is an open access article published by Thieme under the terms of the Creative Commons Attribution-NonDerivative-NonCommercial-License, permitting copying and reproduction so long as the original work is given appropriate credit. Contents may not be used for commercial purposes, or adapted, remixed, transformed or built upon. (https://creativecommons.org/licenses/by-nc-nd/4.0/)

Thieme Medical and Scientific Publishers Pvt. Ltd., A-12, 2nd Floor, Sector 2, Noida-201301 UP, India 
if possible, is confirmatory. The management of ameloblastoma is fascinating yet challenging. A lot of controversies still prevail regarding the mode of interventions, methods of reconstruction, and, it's timing. Despite the plethora of articles, ${ }^{4-9}$ available in the literature, the total consensus has not been reached about its management up till now.

\section{Materials and Methods}

We treated 37 patients of mandibular ameloblastoma at our center between 2009 and 2018. The biopsy confirmed mandibular ameloblastoma patients were included in this prospective study. The rest of the lower jaw and maxillary bone tumor patients were excluded from the study. Out of 37 patients, 2 were treated with curettage and chemical sterilization of the cavity, as they were not ready for the radical surgery. Resection of a tumor with $2 \mathrm{~cm}$ of margin on both sides of a tumor was performed in 35 patients. After wide excision, different modalities were used $(-$ Table 1$)$ to reconstruct the defect. Sole reconstitution metal plate was used in two patients as per their preferences. In one patient, the mandible was not reconstructed, but the soft-tissue bulk was provided with free anterolateral thigh (ALT) flap as the disease was reaching the infratemporal fossa and the whole TM joint and part of zygoma had to be removed. In three patients, the reconstruction was not performed for various medical reasons. In 29 patients, the resultant defect of the mandible was primarily reconstructed with free fibular microvascular flap.

We used a standard degloving incision for the resection. Lip splitting incision can be added without hesitation in cases of large ameloblastoma where wider exposure is required for better resection, and ease of reconstruction. The length of the recipient's vessels, that is, facial artery, the external jugular vein was kept long to obviate the need for vein grafts. We like to include skin paddle as it helps in monitoring the vascularity of the flap. It also takes away the tension from the suture line, so that there are fewer chances of bone and metal exposure. Stereolithographic model ${ }^{10}$ and computerized measurement facilities though precise and time saving are not available with us. Instead, we used a simple mathematical protector for the measurement of the angles of the osteotomy. In cases of mandibular cortex expansion, the 60-degree wedge resection is a good general guide. $\mathrm{HCL}^{11}$ classification of mandibular defects is based on functional, as well as aesthetic factors. It allows different types of reconstructions to be evaluated in a fair and standardized manner. However, our postexcisional defects could not be exactly fitted into this classification. So, just for the practical purpose, and our better understanding we have modified this classification as described in - Table 2. Ramus with lateral body segment reconstruction required one vertical osteotomy (-Figs. 1-3). For condyle reconstruction (-Figs. 4-9), the end of the fibula was rounded and suspended with $1 / 0$ polypropylene suture to the zygoma by drilling a hole in the zygomatic arch. The end of the flap was wrapped with the remaining capsule and surrounding soft tissues. This was performed in four patients. Ramus with central arch restoration ( $\mathbf{- F i g s .} \mathbf{1 0 - 1 2}$ ) required multiple
Table 1 Mode of reconstruction after wide excision

\begin{tabular}{|l|l|}
\hline Reconstructive procedures & No. of patients \\
\hline Free fibular flap & 29 \\
\hline No reconstruction & 3 \\
\hline Metal plate reconstruction & 2 \\
\hline ALT flap to provide bulk & 1 \\
\hline Total & 35 \\
\hline
\end{tabular}

Abbreviation: ALT, anterolateral thigh.

Table 2 Types of mandibular defects and use of free fibula

\begin{tabular}{|l|l|}
\hline Types of mandibular defects & $\begin{array}{l}\text { No. of } \\
\text { cases }\end{array}$ \\
\hline $\mathrm{H}=$ Hemimandible & 4 \\
\hline $\mathrm{H}-\mathrm{CO}=$ hemimandible-Condyle & 6 \\
\hline $\mathrm{R}+\mathrm{L}=$ ramus and lateral segment of mandible & 4 \\
\hline $\begin{array}{l}\mathrm{R}+\mathrm{L}+\mathrm{CO}=\text { ramus + lateral segment + central } \\
\text { arch of mandible }\end{array}$ & 4 \\
\hline $\mathrm{L}=$ lateral segment & 2 \\
\hline $\mathrm{C}=$ central arch & 4 \\
\hline $\mathrm{L}+\mathrm{C}=$ lateral segment + central arch & 3 \\
\hline $\begin{array}{l}\mathrm{L}+\mathrm{C}+\mathrm{L}=\text { lateral segment }+ \text { central arch }+ \text { Lateral } \\
\text { segment }\end{array}$ & 1 \\
\hline Whole mandible except bilateral condyles & 1 \\
\hline Total & 29 \\
\hline
\end{tabular}

osteotomies with varying angles. The central arch is always exciting for the reconstructive surgeon (-Figs. 13-15) was restored in four patients. Reconstruction of the whole mandible except bilateral condyles was found to be most challenging (-Figs. 16-18) fortunately in one patient only.

Interosseous wirings and titanium mini plates were used to fix the bony segments. Facial artery and internal jugular, as well as external jugular veins, were our preferred vessels for anastomoses. We always anastomose two veins as a safeguard against the kinking of anyone. To achieve proper occlusion, intermaxillary fixation was done at the time of bony fixation which is removed at the end of the surgery to facilitate oral hygiene. Donor sites were closed primarily in most patients. Low molecular weight heparin $0.4 \mathrm{~mL}$ subcutaneously was given at the end of the surgery and was continued once a day dosage for five days as prophylaxis.

\section{Results}

Out of 37 patients treated at our center, 19 (51.3\%), patients were male and 18 (48.7\%) were female. We had three (8.1\%) patients between 10 and 20 years of age and five (13.5\%) patients above 40 years of age. This condition was found to be more common between 21 to 40 years of age (78.4\%) in our series. The follow-up ranged from 6 months to 7.7 years with a mean of 5.1 years. Two patients who had opted for curettage of the cavity, despite proper explanation, had a recurrence of the disease within a year. The recurrence was detected on a computed tomography (CT) scan. Both underwent a second round 


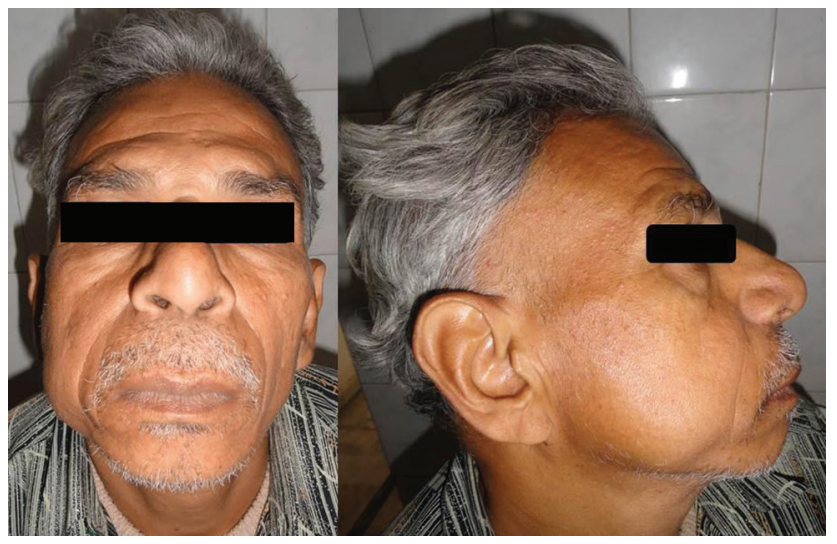

Fig. 1 AP and lateral view of the disease. AP, anteroposterior.

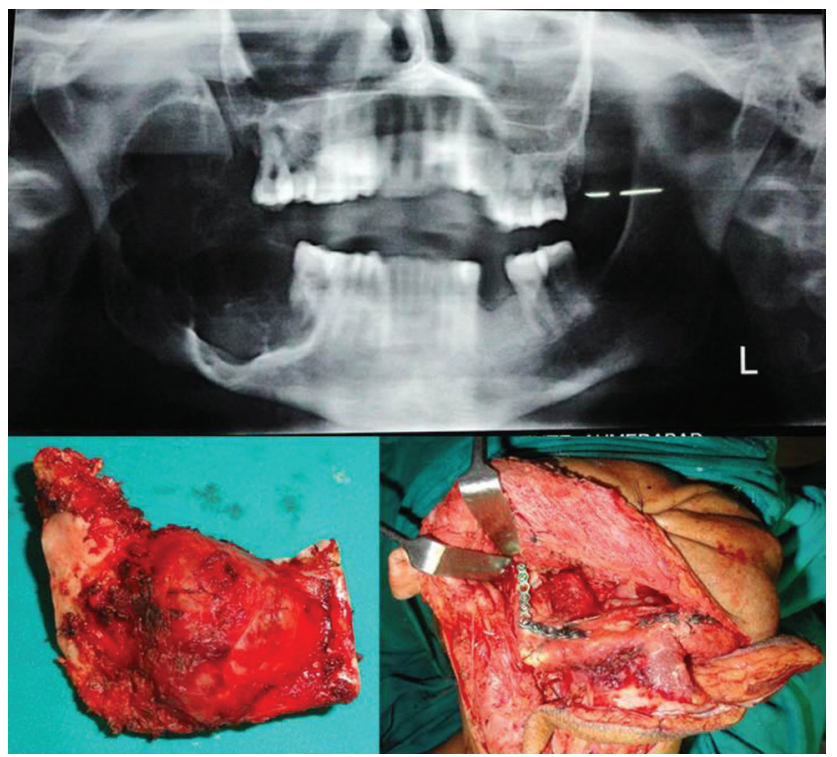

Fig. 2 Preoperative radiological image and Intraoperative excision with flap in situ.

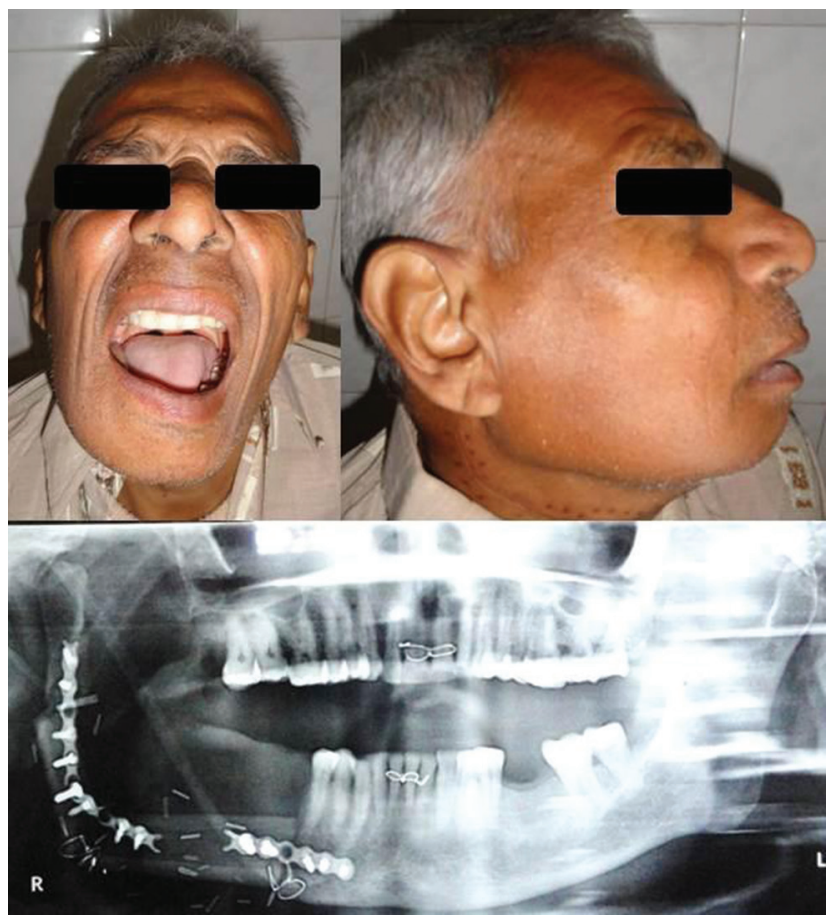

Fig. 3 Postoperative results after ramus and body reconstruction.

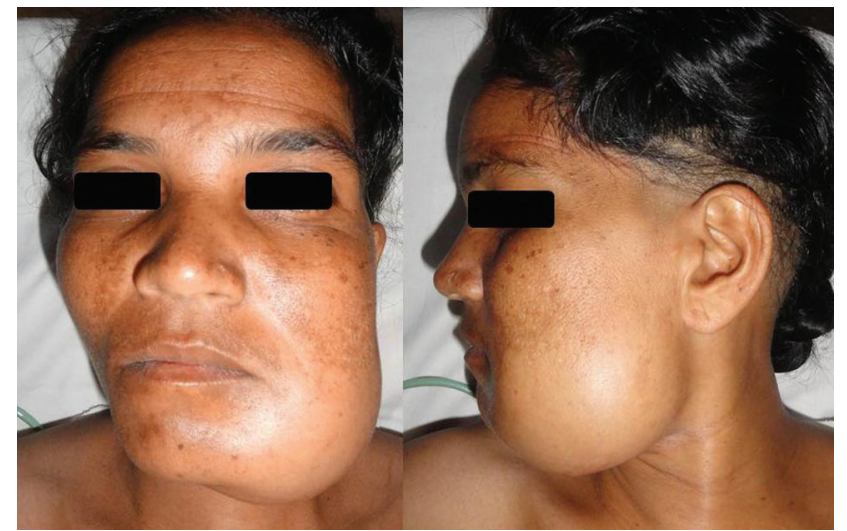

Fig. 4 AP and lateral view of the disease. AP, anteroposterior.

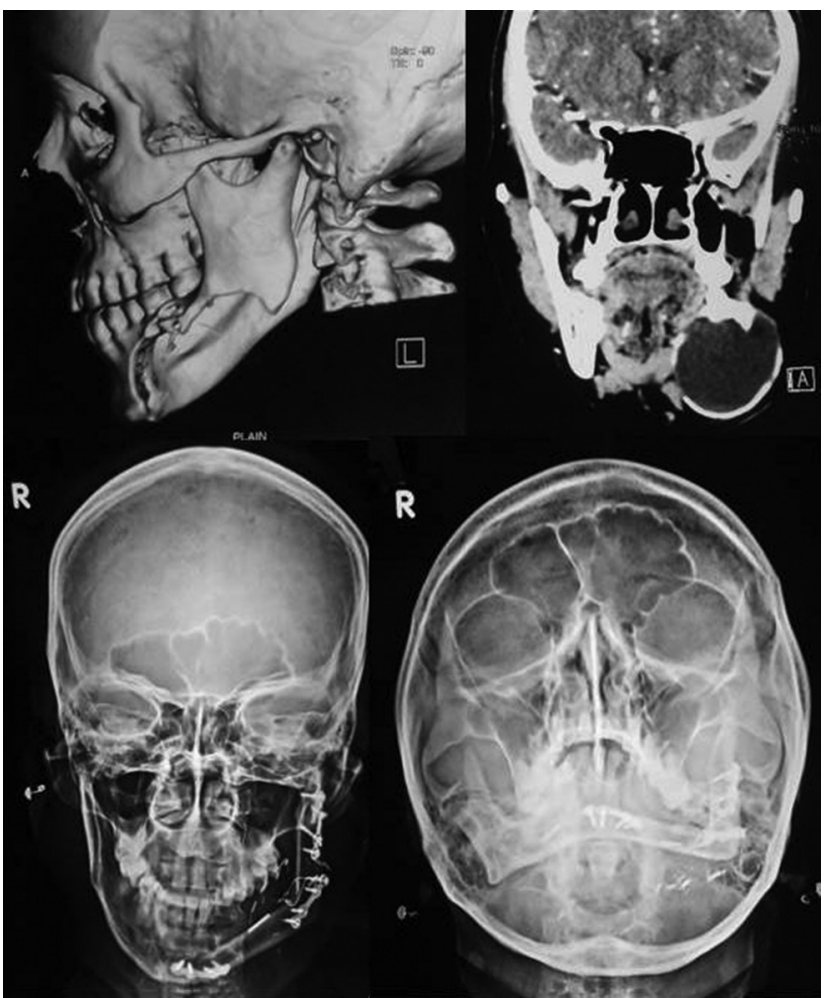

Fig. 5 Preoperative and postoperative radiological images.

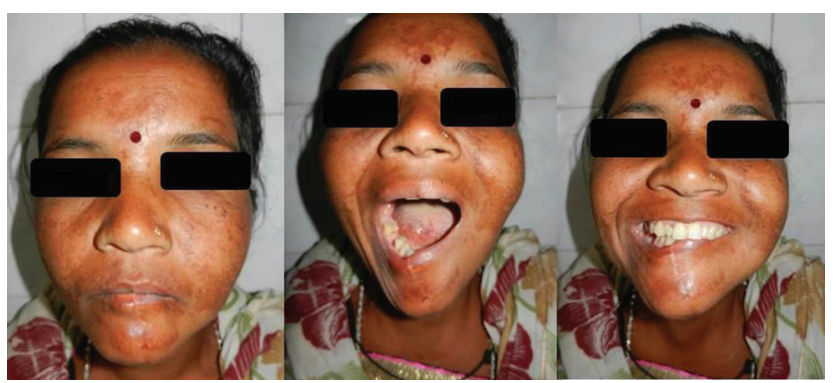

Fig. 6 Postoperative results after body, ramus and condyle reconstruction.

of the curettage with other physicians and lost for follow-up with us.

Out of 35 radical excisions, only 1 (2.85\%) developed recurrence 3 years after the surgery. The probable reason was an 


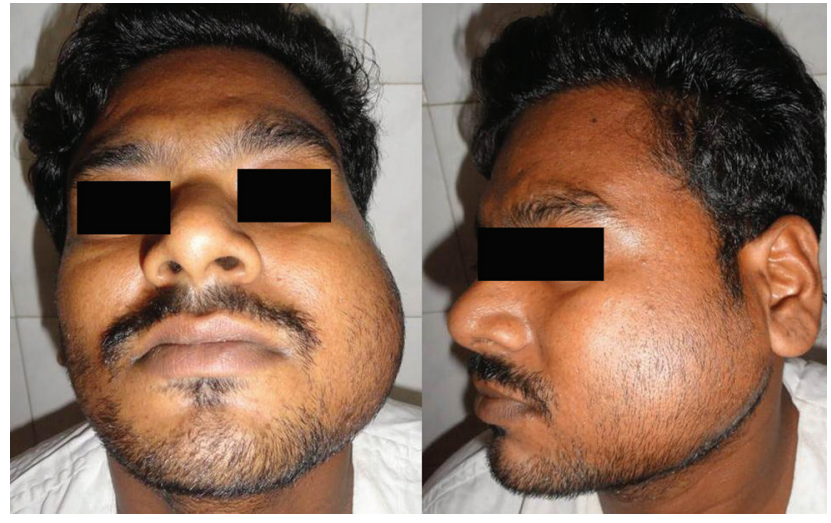

Fig. 7 AP and lateral view of the disease. AP, anteroposterior.
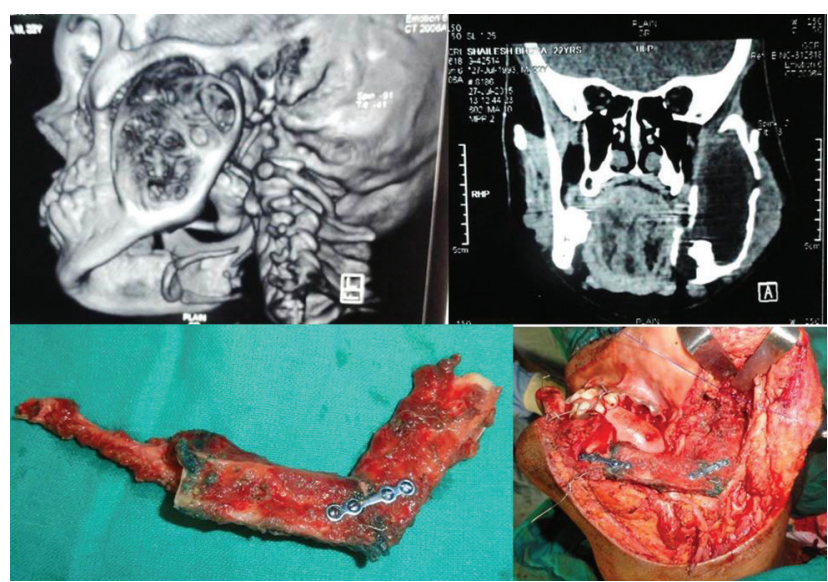

Fig. 8 Preoperative radiological image and Intraoperative excision with flap in situ.

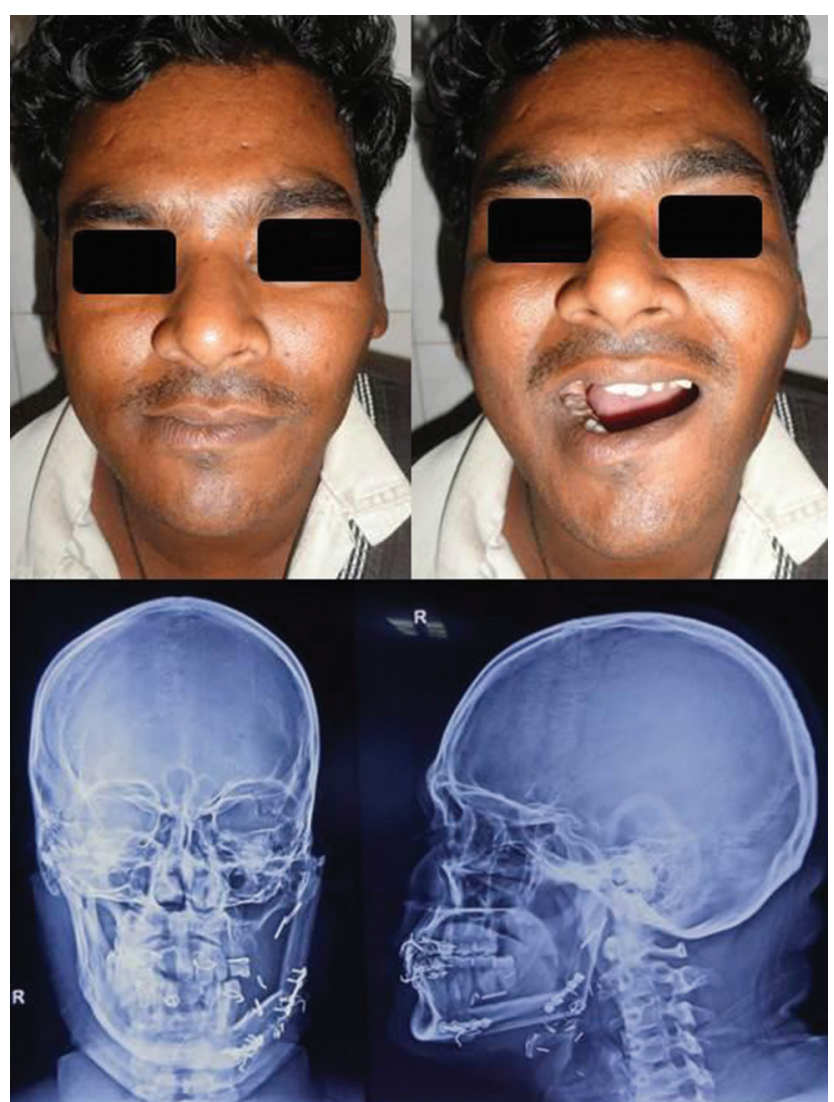

Fig. 9 Postoperative results after body, ramus and condyle reconstruction.

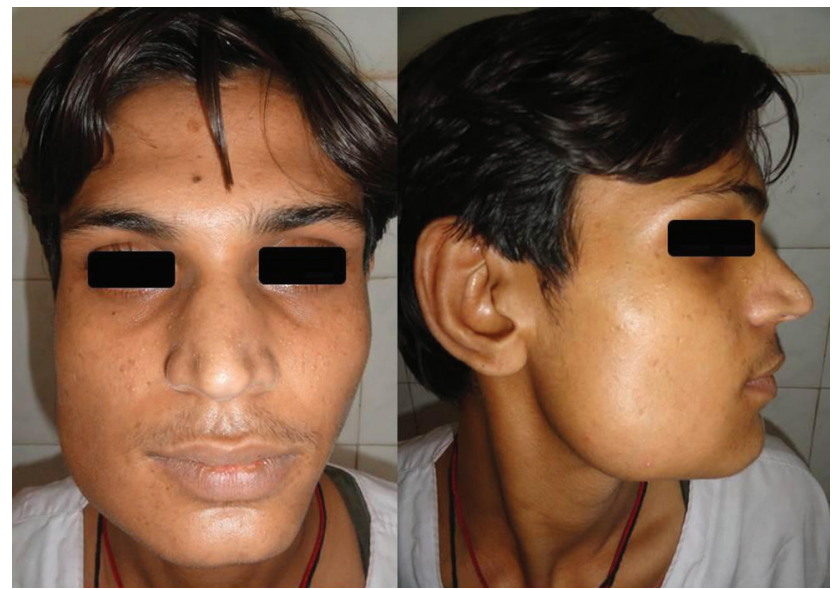

Fig. 10 Preoperative views of the disease.

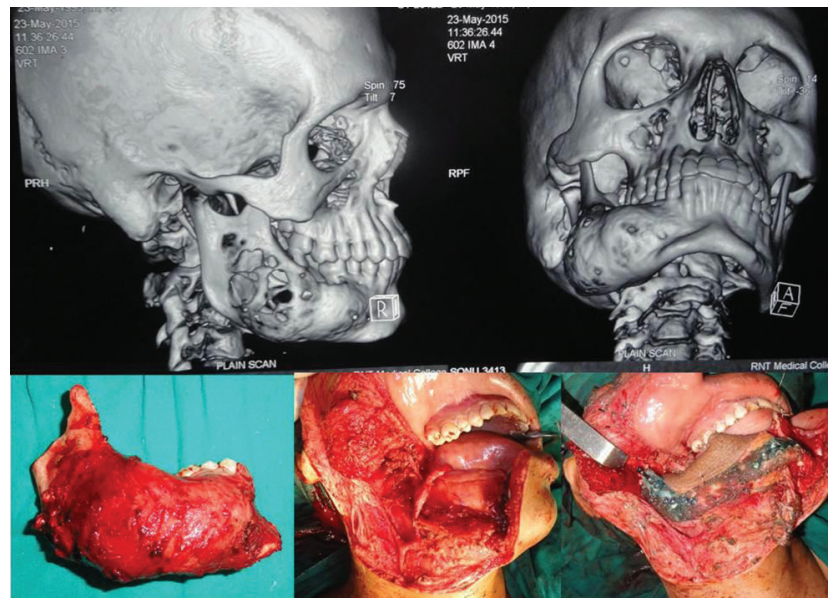

Fig. 11 Preoperative radiological image and Intraoperative excision with flap in situ.

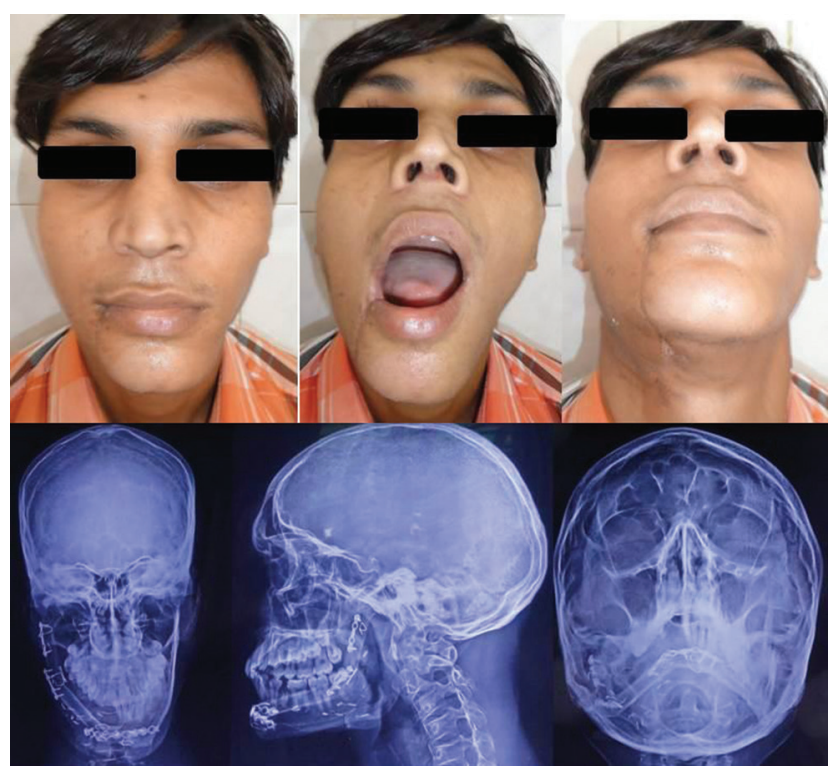

Fig. 12 Postoperative results after ramus to central arch reconstruction. 


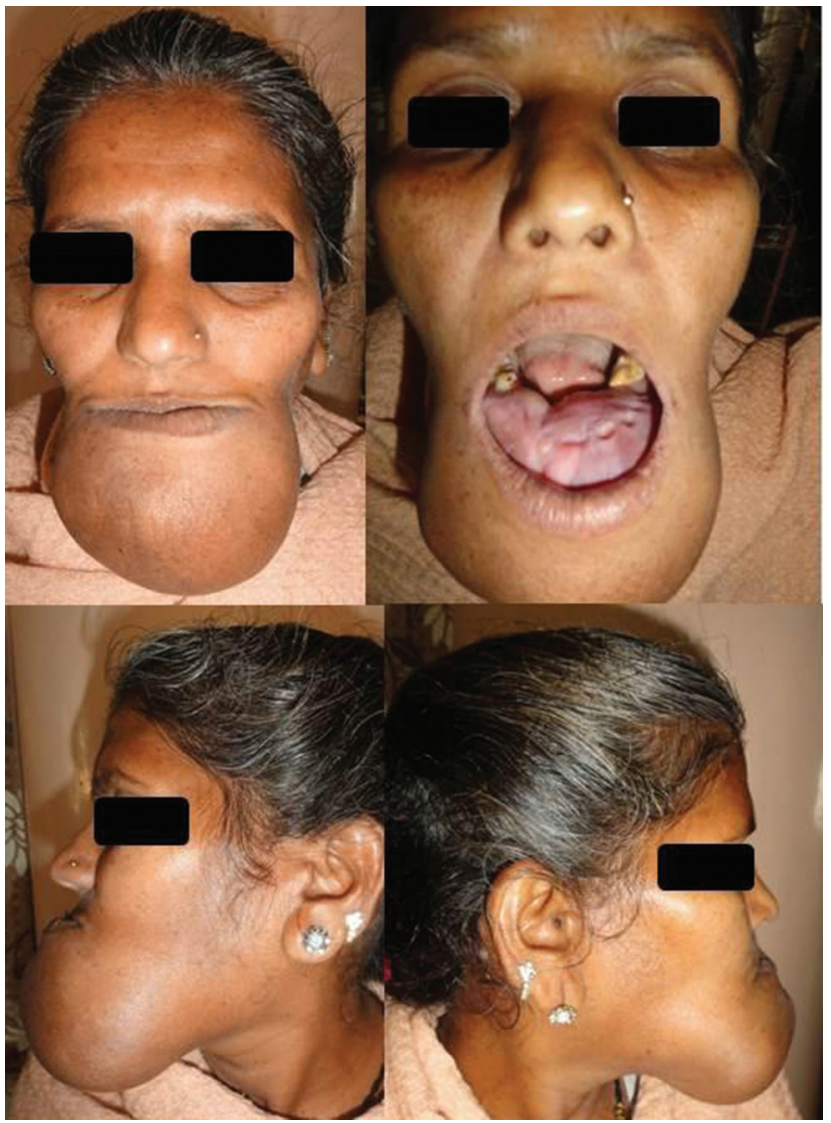

Fig. 13 Preoperative views of the disease.

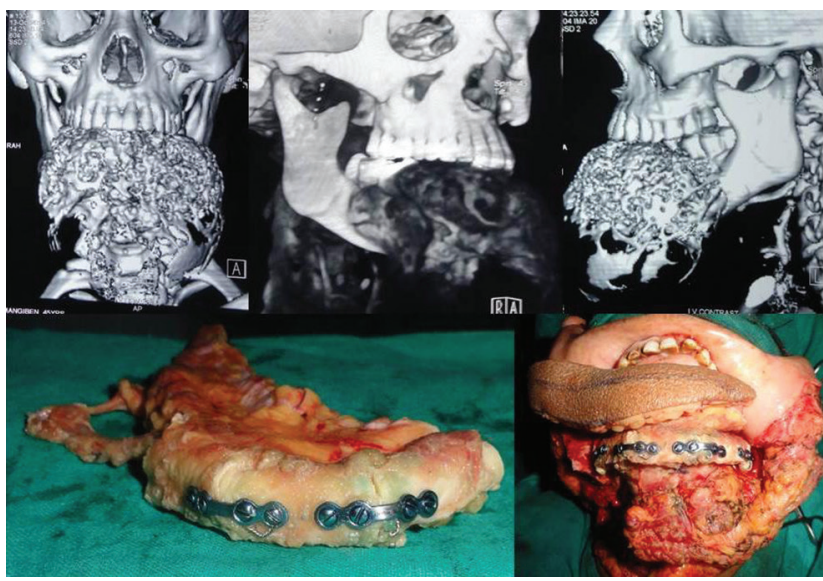

Fig. 14 Preoperative radiological image and Intraoperative excision with flap in situ.

extraosseous spread into the soft tissues at the time of the first presentation. Good three-finger mouth opening, proper occlusion, intelligible speech to relatives and the general public, facial symmetry, and satisfactory cosmetic outcomes were achieved in all 29 patients who were treated with free fibular flaps. Facial symmetry and aesthetic outcomes were evaluated by comparing the present look with predisease facial photographs by patients and their relatives. Four patients, who were treated with wide excision but without any bony

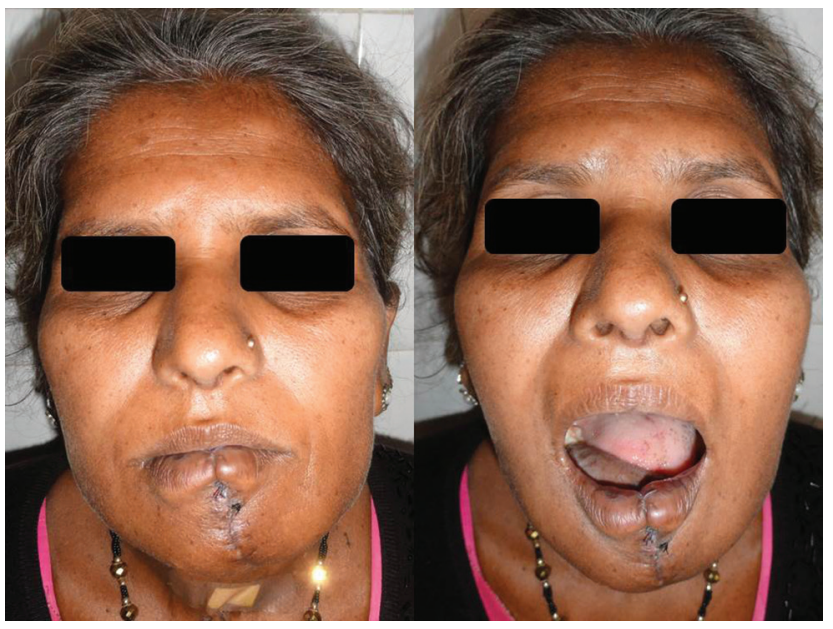

Fig. 15 Postoperative results after central arch reconstruction.

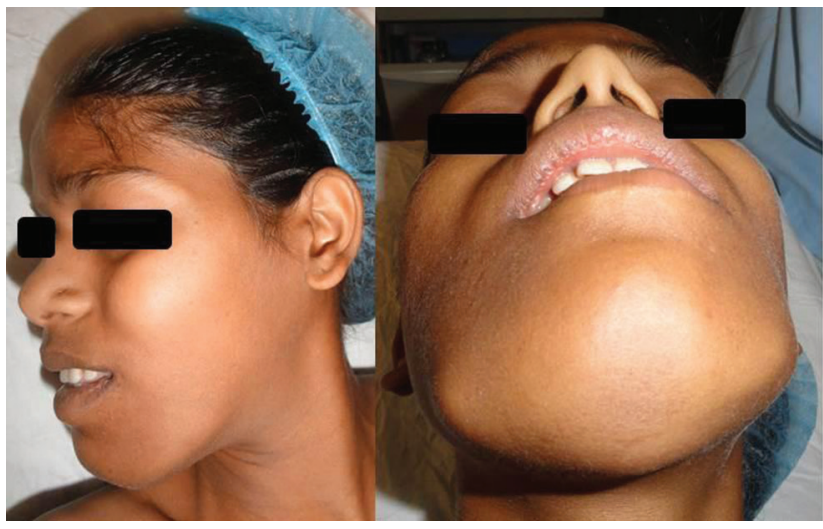

Fig. 16 Preoperative views of the disease.

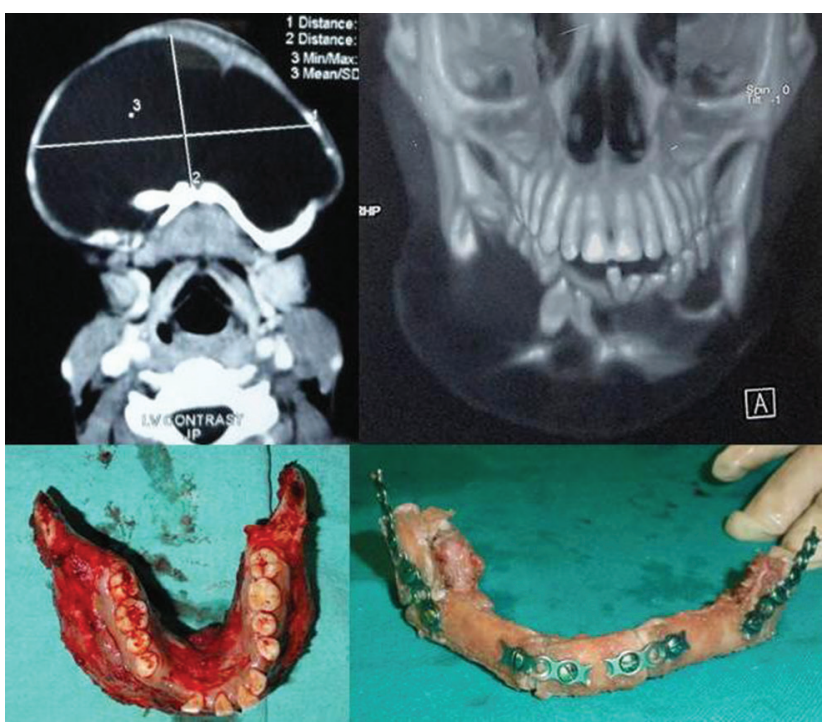

Fig. 17 Preoperative radiological image and Intraoperative excision with flap in situ.

reconstruction, do have few cosmetic and functional problems, but there is no recurrence of the disease till this date. 


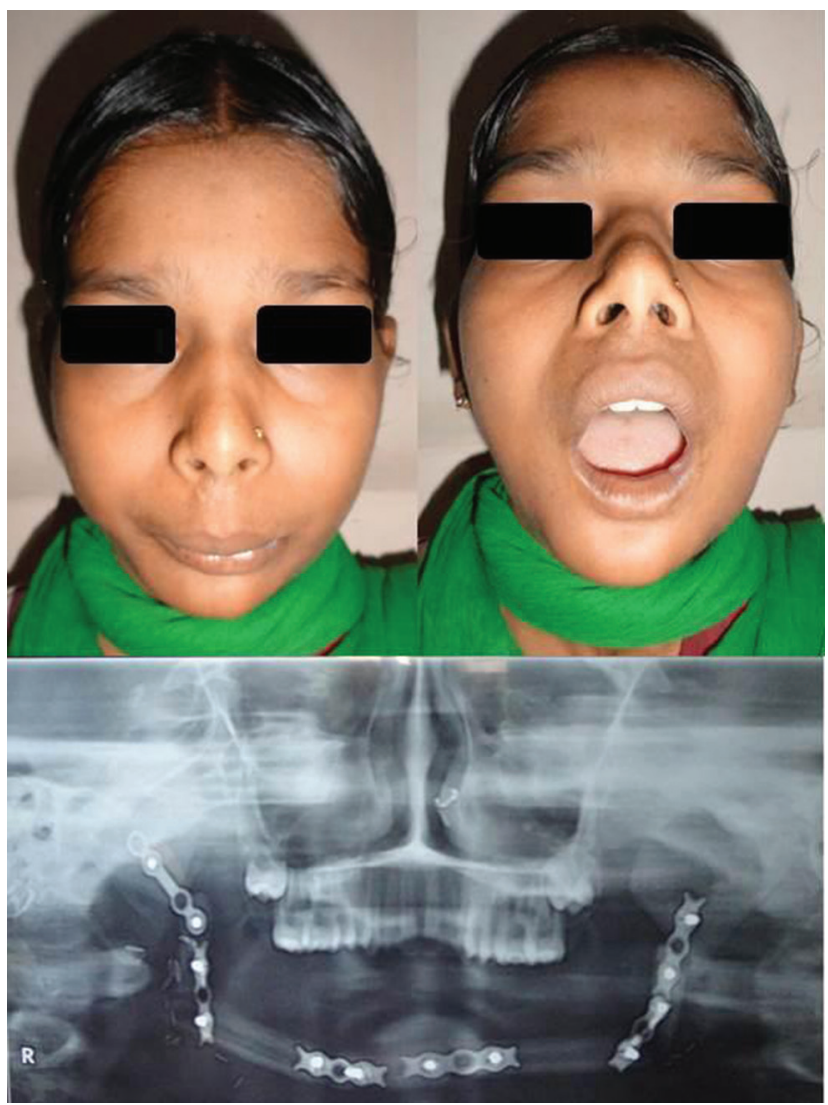

Fig. 18 Postoperative results after ramus to ramus reconstruction.

\section{Discussion}

Complete removal of the disease, restoration of function, good cosmesis, less fibular bone donor site morbidity of the leg, and least recurrence rate are the desirable benchmarks in the treatment of mandibular ameloblastoma. Despite numerous treatment modalities described in the literature, the management of mandibular ameloblastoma remains a subject of a debate ${ }^{4-9}$ with diverse opinions with regard to the role of minimally invasive procedures, safe margins of resection and, its overall effect on recurrence rate, timing and methods of reconstruction with proper donor site selections.

Minimal invasive procedures like curettage, enucleation, or marsupialization with or without electrical or chemical sterilization by cautery, phenol, or Carnoy's solution $^{12,13}$ is commonly being performed. However, minimally invasive methods like enucleation and curettage $e^{7,8,14,15}$ have undesirable recurrence rates of 55 and 90\%, respectively. Furthermore, the metastases following conservative management have been described. ${ }^{16}$ Huge, recurrent, irresectable tumors carry around 30\% mortality. ${ }^{15}$ The role of radiotherapy is limited. ${ }^{17,18}$ Even though the unanimous consensus is still eluding us, based on our little experience and available literature, we try to avoid minimally invasive procedures in adult patients as far as possible. Vast available literature also backs this argument. ${ }^{7,814,15}$ The conservative and radical en bloc segmental resection with or without reconstruction of bony defect has also been reported ${ }^{14,19}$ with a recurrence rate of 31 to $33 \%$ after conservative and $7.1 \%$ after radical resection. ${ }^{5,19}$

There are proponents and opponents of both treatment strategies. The proponents of minimally invasive approach $^{5,6,9}$ believe that ameloblastomas though, locally invasive, are essentially benign. "Excessive resection means excessive treatment" ${ }^{5}$ which can lead to significant functional, aesthetic, and reconstructive problems ${ }^{20}$ with very high morbidity. There is no harm in repeating the procedure in the event of a recurrence. In contrast, the proponents of the radical approach ${ }^{7,8}$ believe that, although these tumors are histologically benign, they are locally aggressive and the clinical behavior must be regarded as lying somewhere between benign and malignant lesions. Hence, they should be treated like malignant lesions. The lower recurrence rates are in favor of this argument.

The key reason for recurrence is unintended inadequate removal. The architectural pattern of the ameloblastoma is such that the border of a tumor within the cancellous bone can extend beyond the apparent macroscopic surface and the radiographic boundaries of the lesion..$^{21}$ Marx et al, ${ }^{22}$ found tumor cells 2.3 to $8 \mathrm{~mm}$ beyond macroscopic or radiographic margins within the cancellous bone. Infiltration of the fibrous wall of the cyst with tumor nodules, radiologically invisible "microcysts," and "daughter cysts" are similarly important. Curettage can be less suitable in this type of situation. Inadvertent cortical perforation during curettage can lead to the dissemination of a tumor and recurrence. The aggressive biological behavior of a tumor has a significant role to play. The spread of a tumor along the inferior alveolar nerve has also been reported. ${ }^{23,24}$ The lack of adequate reconstructive facilities and reluctance on the part of patients to undergo long and extensive surgeries compels the treating surgeon to opt for minimally invasive modalities of the treatment.

One more reason to choose radical resection is the difficulties in early identification of recurrence. Clinical examination has limited value unless the swelling has grown large. Once curetted, the typical septate or honeycomb appearance is lost on X-Ray. Only CT scans or MRIs are helpful in prompt identification. Investigations and frequent hospital visits are time consuming and add to the cost. From the surgeon's perspective, the recurrence many a time presents resective, as well as reconstructive challenges.

Considering the biological behavior of ameloblastoma, possibilities of the presence of tumor cells beyond macroscopic or radiographic margins within the cancellous bone, high recurrence following the minimally invasive line of treatment, and difficulty in early identification and its management at our institute, the segmental resection is performed with $2-\mathrm{cm}$ margin beyond the radiological limit to ensure that all microlesions are removed. The frozen section examination of margins, ${ }^{22,25}$ though time consuming is performed only in doubtful cases. This radical excision also allows for immediate reconstruction to be carried without much risk of recurrence.

The timing of reconstruction ${ }^{26-28}$ has largely remained a subject of debate. Proponents of secondary reconstruction believe that the reconstruction should be postponed for a later date as the recurrence rates of mandibular ameloblastoma 
are high. Spacing surgeries give ample time for adequate maturation of the tissues. In the event of unfortunate recurrence, the critical tissue resources for the reconstruction, as well as financial resources, are lost. Despite these advantages of late reconstruction, the primary reconstruction ${ }^{26}$ is always preferred because of its surgical, functional, and psychological advantages. Radical excision always leaves behind large tissue defects. Even a cm tumor produces a defect of $5 \mathrm{~cm}$. If not reconstructed, the morbidity is very high. Soft tissue fibrosis wound bed contamination, obliterated, or encased recipient vessels required for microanastomosis pose additional surgical challenges. The risk of flap failure and other postoperative complications are more compared with primary reconstruction. ${ }^{29}$ The reconstruction of anterior defects and shaping of the natural arch had been found unsatisfying. Additional surgeries are required for proper corrections. ${ }^{30}$ The expectations of a return to normalcy are also high. Less lifetime is lost if the procedure is performed primarily. ${ }^{31}$ Health-related quality of life (QOL) studies have demonstrated that immediate reconstruction significantly improves QOL and that most patients prefer immediate reconstruction. ${ }^{32-36}$ Even in our series also, we have found the primary reconstruction very satisfactory.

The proper selection of reconstructive modality is equally important for a favorable outcome. Metal plate, ${ }^{37}$ bioimplant containing BMP-7, ${ }^{38}$ distraction osteogenesis, ${ }^{39}$ and osseous flaps are few of the options available for reconstruction. Metal plate fixation ${ }^{40}$ is a simpler substitute where the microvascular facility is not available or when a patient's medical condition does not permit long hours of surgery. However, it is temporary and works only as a spacer. The screws become loose over a period of time and plate tends to extrude. Eventually, the plate has to be replaced by the bone. Distraction osteogenesis has a very limited role to play in ameloblastomas, ${ }^{41,42}$ while the longterm results of bioimplants are not available. Ideally, the bone should be replaced with a bony tissue while involved mucosa or skin has to be replaced with the soft tissue. The advantages of osteocutaneous flaps containing fibula above other osseous flaps are well known. Apart from the long- and high-quality bone supply, the soft tissue components harvested are a good replacement for buccal mucosa or overlying skin when needed. The deepithelialized skin paddle or soleus muscle provides the necessary bulk. Suitable donor vessels allow for anastomoses to large vessels in the neck. Placement of osseointegrated dental implants is possible at the same sitting or a later date. ${ }^{43}$ Two teams can work simultaneously to save the operative time. There is a minimum donor site morbidity and disfigurement. There is a potential for further bony growth in young patients. ${ }^{44}$ In our series, we could reconstruct all defects of the mandible with the fibula which is well evident from - Table $\mathbf{2}$ and the images.

Our aggressive surgical approach is probably influenced by the excellent functional and aesthetic results of immediate reconstruction of the mandible, minimal recurrence rates (2.85\%), and less morbidity in adult patients. The secondary reconstruction is always difficult and many times are not possible. As the near-total cure can be achieved with a radical approach, all resources should be spent on thorough excision and reconstruction.

\section{Conclusion}

Ameloblastoma is a benign, yet locally invasive odontogenic tumor with a high recurrence rate when associated with an inappropriate initial therapeutic approach. The first operation, especially radical, affords the best chance for cure. From our experience, we recommend radical surgical resection and simultaneous reconstruction of the jaw with the free fibular flap in mandibular ameloblastoma.

\section{Conflict of Interest}

None declared.

\section{Declaration}

The patient's consent has been obtained for the publication of their photographs.

\section{Conflict of Interest}

None declared.

\section{References}

1 Hertog D, van der Waal I. Ameloblastoma of the jaws: a critical reappraisal based on a 40-years single institution experience. Oral Oncol 2010;46(1):61-64

2 Small IA, Waldron CA. Ameloblastomas of the jaws. Oral Surg Oral Med Oral Pathol 1955;8(3):281-297

3 Barnes L, Eveson JW, Reichart PA, Sidransky D, World Health Organization Classification of Tumours. Pathology and Genetics. Head and Neck Tumours. Lyon: World Health Organization International Agency for Research on Cancer, IACR Press:; 2005

4 Vohra FA, Hussain M, Mudassir M. Ameloblastomas, and their management: a review. J Surg Pakistan 2009;14(3):136-142

5 Ueno S, Mushimoto K, Shirasu R. Prognostic evaluation of ameloblastoma based on histologic and radiographic typing. J Oral Maxillofac Surg 1989;47(1):11-15

6 Feinberg SE, Steinberg B. Surgical management of ameloblastoma. Current status of the literature. Oral Surg Oral Med Oral Pathol Oral Radiol Endod 1996;81(4):383-388

7 Sampson DE, Pogrel MA. Management of mandibular ameloblastoma: the clinical basis for a treatment algorithm. J Oral Maxillofac Surg 1999;57(9):1074-1077, discussion 1078-1079

8 Mehlisch DR, Dahlin DC, Masson JK. Ameloblastoma: a clinicopathologic report. J Oral Surg 1972;30(1):9-22

9 Sammartino G, Zarrelli C, Urciuolo V, et al. Effectiveness of a new decisional algorithm in managing mandibular ameloblastomas: a 10-years experience. Br J Oral Maxillofac Surg 2007; 45(4):306-310

10 Infante-Cossio P, Gacto-Sanchez P, Gomez-Cia T, GomezCiriza G. Stereolithographic cutting guide for fibula osteotomy. Oral Surg Oral Med Oral Pathol Oral Radiol 2012;113(6): 712-713, author reply 712

11 Boyd JB, Gullane PJ, Rotstein LE, Brown DH, Irish JC. Classification of mandibular defects. Plast Reconstr Surg 1993; 92(7):1266-1275

12 Chapelle KAOM, Stoelinga PJW, de Wilde PC, Brouns JJ, Voorsmit RA. Rational approach to diagnosis and treatment of ameloblastomas and odontogenic keratocysts. $\mathrm{Br} \mathrm{J}$ Oral Maxillofac Surg 2004;42(5):381-390

13 Meer S, Galpin JS, Altini M, Coleman H, Ali H. Proliferating cell nuclear antigen and Ki67 immunoreactivity in ameloblastomas. Oral Surg Oral Med Oral Pathol Oral Radiol Endod 2003;95(2):213-221 
14 Pogrel MA, Montes DM. Is there a role for enucleation in the management of ameloblastoma. ? Int J Oral Maxillofac Surg 2009;38(8):807-812

15 Shatkin S, Hoffmeister FS. Ameloblastoma: a rational approach to therapy. Oral Surg Oral Med Oral Pathol 1965;20(4):421-435

16 Slootweg PJ, Müller H. Malignant ameloblastoma or ameloblastic carcinoma. Oral Surg Oral Med Oral Pathol 1984;57(2): 168-176

17 Reichart PA, Philipsen HP, Sonner S. Ameloblastoma: biological profile of 3677 cases. Eur J Cancer B Oral Oncol 1995;31B(2):86-99

18 Miyamoto CT, Brady LW, Markoe A, Salinger D. Ameloblastoma of the jaw. Treatment with radiation therapy and a case report. Am J Clin Oncol 1991;14(3):225-230

19 Nakamura N, Higuchi Y, Mitsuyasu T, Sandra F, Ohishi M. Comparison of long-term results between different approaches to ameloblastoma. Oral Surg Oral Med Oral Pathol Oral Radiol Endod 2002;93(1):13-20

20 Kim SG, Jang HS. Ameloblastoma: a clinical, radiographic, and histopathologic analysis of 71 cases. Oral Surg Oral Med Oral Pathol Oral Radiol Endod 2001;91(6):649-653

21 Ghandhi D, Ayoub AF, Pogrel MA, MacDonald G, Brocklebank LM, Moos KF. Ameloblastoma: a surgeon's dilemma. J Oral Maxillofac Surg 2006;64(7):1010-1014

22 Marx RE, Smith BH, Smith BR, Fridrich KL. Swelling of the retromolar region and cheek associated with limited opening. J Oral Maxillofac Surg 1993;51(3):304-309

23 Nakamura N, Mitsuyasu T, Higuchi Y, Sandra F, Ohishi M. Growth characteristics of ameloblastoma involving the inferior alveolar nerve: a clinical and histopathologic study. Oral Surg Oral Med Oral Pathol Oral Radiol Endod 2001;91(5):557-562

24 Wu TC, Chen Z, Tian FC, Tian QZ, You CT. Ameloblastoma of the mandible treated by resection, preservation of the inferior alveolar nerve, and bone grafting. J Oral Maxillofac Surg 1984;42(2):93-96

25 Williams TP. Management of ameloblastoma: a changing perspective. J Oral Maxillofac Surg 1993;51(10):1064-1070

26 Schusterman MA, Harris SW, Raymond AK, Goepfert H. Immediate free flap mandibular reconstruction: significance of adequate surgical margins. Head Neck 1993;15(3):204-207

27 Lawson W, Loscalzo LJ, Baek SM, Biller HF, Krespi YP. Experience with immediate and delayed mandibular reconstruction. Laryngoscope 1982;92(1):5-10

28 Kumar BP, Venkatesh V, Jeevan Kumar KA, Yashwanth Yadav B, Ram Mohan S. Mandibular Reconstruction: Overview. J Maxillofac Oral Surg 2016;15(4):425-441

29 Andrade W, Grover H, Lipa JE, Bang C, Gilbert R, Neligan PC. Reconstructive options and outcomes in primary vs. secondary mandibular reconstruction. J Reconstr Microsurg 2006;22A008 doi: 10.1055/s-2006-958656

30 Seitz O, Harth M, Ghanaati S, et al. Secondary mandibular reconstruction after oral squamous cell carcinoma resection: clinical reevaluation of transport disk distraction osteogenesis. J Craniofac Surg 2010;21(1):59-63
31 Boyd JB, Mulholland RS, Davidson J, et al. The free flap and plate in oromandibular reconstruction: long-term review and indications. Plast Reconstr Surg 1995;95(6):1018-1028

32 Cordeiro PG, Hidalgo DA. Conceptual considerations in mandibular reconstruction. Clin Plast Surg 1995;22(1):61-69

33 Baker A, McMahon J, Parmar S. Immediate reconstruction of continuity defects of the mandible after tumor surgery. J Oral Maxillofac Surg 2001;59(11):1333-1339

34 Li X, Zhu K, Liu F, Li H. Assessment of quality of life in giant ameloblastoma adolescent patients who have had mandible defects reconstructed with a free fibula flap. World J Surg Oncol 2014;12:201

35 Netscher DT, Meade RA, Goodman CM, Alford EL, Stewart MG. Quality of life and disease-specific functional status following microvascular reconstruction for advanced (T3 and T4) oropharyngeal cancers. Plast Reconstr Surg 2000;105(5):1628-1634

36 Weymuller EA, Yueh B, Deleyiannis FWB, Kuntz AL, Alsarraf R, Coltrera MD. Quality of life in patients with head and neck cancer: lessons learned from 549 prospectively evaluated patients. Arch Otolaryngol Head Neck Surg 2000; 126(3):329-335, discussion 335-336

37 JoYY, Kim SG, Kim MK, Shin SH, Ahn J, SeokH; Jo YY1. Mandibular reconstruction using a customized three-dimensional titanium implant applied on the lingual surface of the mandible. J Craniofac Surg 2018;29(2):415-419

38 Clokie CM, Sándor GK. Reconstruction of 10 major mandibular defects using bioimplants containing BMP-7. J Can Dent Assoc 2008;74(1):67-72

39 González-Garcia R, Rubio-Bueno P, Naval-Gías L, et al. Internal distraction osteogenesis in mandibular reconstruction: clinical experience in 10 cases. Plast Reconstr Surg 2008;121(2): 563-575, discussion 576-577

40 Bede SYH, Ismael WK, Hashim EA. Reconstruction platerelated complications in mandibular continuity defects. Oral Maxillofac Surg 2019;23(2):193-199

41 Balaji SM. Total reconstruction of mandible by transport distraction after complete resection for benign and malignant tumors. Indian J Dent Res 2016;27(2):205-212

42 González-García R, Naval-Gías L. Transport osteogenesis in the maxillofacial skeleton: outcomes of a versatile reconstruction method following tumor ablation. Arch Otolaryngol Head Neck Surg 2010;136(3):243-250

43 Chana JS, Chang YM, Wei FC, et al. Segmental mandibulectomy and immediate free fibula osteoseptocutaneous flap reconstruction with endosteal implants: an ideal treatment method for mandibular ameloblastoma. Plast Reconstr Surg 2004;113(1):80-87

44 Ghert M, Colterjohn N, Manfrini M. The use of free vascularized fibular grafts in skeletal reconstruction for bone tumors in children. J Am Acad Orthop Surg 2007;15(10):577-587 